\title{
Análise Sazonal dos Parâmetros Biofísicos Utilizando o Sensor MODIS para o Estado de Alagoas
}

\author{
Felipe Souza dos $\operatorname{Santos}^{1}$ (D), Heliofábio Barros Gomes ${ }^{2}$ (D), Glauber Vinícius Pinto de Barros ${ }^{1}$ (D), \\ Laurizio Emanuel Ribeiro Alves ${ }^{3}$ (D), Djane Fonseca da Silva ${ }^{2}$ (D), Rafaela Lisboa Costa ${ }^{2}$ (D), \\ Fabricio Daniel dos Santos Silva ${ }^{2}$ (D) José Francisco de Oliveira Júnior ${ }^{2}$ \\ ${ }^{1}$ Programa de Pós-Graduação em Meteorologia, Instituto de Ciências Atmosféricas, \\ Universidade Federal de Alagoas, Maceió, AL, Brasil. \\ ${ }^{2}$ Instituto de Ciências Atmosféricas, Universidade Federal de Alagoas, Maceió AL, Brasil. \\ ${ }^{3}$ Programa de Pós-Graduação em Meteorologia, Instituto Nacional de Pesquisas Espaciais, \\ Cachoeira Paulista, SP, Brasil.
}

Recebido em: 29 de Junho de 2020 - Aceito em: 29 de Outubro de 2020

\begin{abstract}
Resumo
O monitoramento dos parâmetros biofísicos de uma determinada região é de suma importância para sua população, tendo em vista os impactos causados por fenômenos climáticos de grande escala e a sazonalidade dos sistemas meteorológicos que afetam a região. Portanto, o objetivo do estudo é analisar a sazonalidade dos parâmetros biofísicos Índice de Vegetação por Diferença Normalizada (IVDN) e temperatura da superfície terrestre (TST) assim como, sua interação com a chuva no Estado de Alagoas para os anos de 2001 e 2016 sobe influência de La Niña. Foram utilizados produtos de IVDN e TST do sensor MODIS, satélite TERRA, processados através do software Qgis 2.18.3. Inicialmente, foram realizados cálculos com os fatores de ajuste nas imagens de IVDN e TST, e posteriormente foram elaborados os mapas temáticos. Os resultados obtidos mostram um aumento no último trimestre do ano de 2016 nas classes de vegetação rala e solo exposto e uma diminuição da vegetação densa em relação ao ano de 2001, nas demais classes houve uma variabilidade sazonal da cobertura vegetal. Os mapas de TST apresentam correlação forte com o IVDN, mostrando uma relação inversamente proporcional entre os parâmetros. Na precipitação verificou-se a sua influência direta na resposta do IVDN e TST, devido ao tipo de vegetação encontrado na região.
\end{abstract}

Palavras-chave: sensoriamento remoto, sistemas meteorológicos, índices de vegetação.

\section{Seasonal Analysis of Biophysical Parameters using the MODIS Sensor for the State OF Alagoas}

\begin{abstract}
The monitoring of the biophysical parameters of a given region is of paramount importance for its population, in view of the impacts caused by large-scale climatic factors and the seasonality of the meteorological systems that affect the region. Therefore, the objective of the study is analyzing the seasonality of the biophysical parameters Index of Vegetation by Normalized Difference (IVDN) and Land surface temperature (LST) as well, TST interaction with rainfall in the State of Alagoas for the years 2001 and 2016 rises under the influence of La Niña. IVDN and TST product TST from the MODIS sensor, TERRA satellite, were processed using the Qgis 2.18.3 software. Initially, calculations were performed with the adjustment factors in the IVDN and TST images, and later the thematic maps were prepared for the analyzes. The result TST obtained show an increase in the last quarter of 2016 in the classes of thin vegetation and exposed soil and a decrease in dense vegetation compared to 2001, in the other classes there is a seasonal variability of the vegetation cover. TST maps have direct influence with IVDN, showing an inversely proportional relationship between the parameters. In precipitation, TST direct influence on the response of IVDN and TST was verified, due to the type of vegetation found in the region.
\end{abstract}

Keywords: remote sensing, meteorological systems, vegetation indexes.

Autor de correspondência: Felipe Souza dos Santos, Felipe.souza@.cat.ufal.br. 


\section{Introdução}

Os produtos desenvolvidos via Sensoriamento Remoto (SR) orbital vêm se tornando uma importante ferramenta para as mais variadas aplicações, principalmente aqueles que estão relacionados a avaliação, o manejo, o gerenciamento e a gestão de recursos naturais Vasconcelos; Novo e Donalisio (2006). Ademais, o SR possibilita a análise espaço-temporal tanto do uso e ocupação do solo quanto da precipitação pluviométrica (Simões et al., 2017) e Arruda (2015).

A avaliação do uso e cobertura do solo foi baseada no índice de vegetação, o qual é definido como uma medida radiométrica adimensional que indica o vigor da vegetação e outros constituintes do solo Jesen (2009). O índice selecionado para este estudo já é consolidado pela literatura para mapear e avaliar o uso e cobertura do solo, denominado (IVDN) Rouse et al. (1974), inúmeros estudos vêm sendo desenvolvidos ao longo dos anos por vários autores, tais como (Allen et al., 2002; Santos, 2012).

O monitoramento da chuva por meio de SR é uma das formas mais econômica para mitigação de possíveis desastres naturais devido aos fenômenos meteorológicos ligados as fortes chuvas, intensas nuvens convectivas Cumulonimbus, zonas frontais, complexos convectivos de mesoescala, entre outros fenômenos atmosféricos que afetam a região Nascimento (2005) e Lima (2005). Segundo Marengo et al. (2016), os moradores da região do Nordeste do Brasil (NEB), ainda sofrem com os efeitos causados pelos cenários de extrema seca.

Um dos parâmetros meteorológicos primordiais que compõem o balanço superficial de energia (BSE) é a Temperatura de Superfície Terrestre (TST), sendo a partir dela, possível monitorar os processos de degradação, desertificação e, principalmente mudanças climáticas (Peixoto, 2009; Santos, 2020). Por meio da TST é possível avaliar os processos físicos à superfície em escala regional e global, sendo fundamental para os processos de evaporação e transpiração da vegetação, ainda usado como indicador de degradação terrestre (Araújo e Di Pace, 2010; Correia Filho et al., 2019).

O objetivo desta pesquisa será estimar os parâmetros biofísicos e compará-los juntamente com a precipitação para todo o Estado de Alagoas utilizando técnicas de geoprocessamento e imagens orbitais do sensor Moderate Resolution Imaging Spectroradiometer (MODIS) para 2001 e 2016 anos de La Niña. Para mais, avaliar e analisar as alterações dos parâmetros biofísicos ocorridos sobre a área de estudo.

\section{Materiais e Métodos}

\section{1. Área de estudo}

$\mathrm{O}$ estado de Alagoas pertence à região NEB e faz fronteira com Pernambuco, Sergipe e Bahia, além de ser banhado pelo oceano Atlântico. Está situado entre as coordenadas geográficas de latitude $9^{\circ} 34^{\prime} 12$ " S e longitude $36^{\circ} 33^{\prime} 0^{\prime \prime}$ W. A extensão territorial de Alagoas é de $27.767,661 \mathrm{~km}^{2}$, o estado é composto por 102 municípios e uma população de aproximadamente 2.822 .821 habitantes (2001) e 3.120.494 habitantes (2016) (Fig. 1). O clima na maior parte do território alagoano é tropical com temperaturas entre $18{ }^{\circ} \mathrm{C}$ e $26^{\circ} \mathrm{C}$ e no interior do Estado há regiões com clima semiárido, a estação que ocorre os maiores índices de chuva é o inverno IBGE (2016).

A principal característica climática da região é a irregularidade da precipitação pluviométrica e a pouca variação sazonal da radiação solar, do fotoperíodo e da temperatura do ar Lyra et al. $(2014,2016)$. A proximidade da linha do Equador é fator que condiciona o número elevado de horas de incidência solar por ano e, consequentemente, índices acentuados de evapotranspiração Barros et al. (2012). A vegetação é composta por floresta tropical, mangues litorâneos e caatinga. Os principais rios são: Ipanema, Moxotó, Mundaú, Paraíba, São Francisco IBGE (2016). O Estado de Alagoas é dividido geograficamente em três mesorregiões: Mesorregião do Agreste Alagoano, Mesorregião do Leste Alagoano e Mesorregião do Sertão Alagoano IBGE (2011).

\subsection{Dados e produtos de satélite}

No estudo foram usados os dados de TST e IVDN gerados por meio do sensor MODIS, a bordo dos satélites TERRA/AQUA. Foram selecionados para o estudo os anos de 2001 e 2016, para esses anos a região encontra-se sobre influência de La Niña, nas quais o oceano Pacífico Equatorial está mais frio. Tendo em vista que as imagens utilizadas neste estudo são mensais, as informações contidas nas imagens passaram por um pré-processamento, onde foram selecionadas cenas com menor cobertura de nuvens, que em seguida foram interpoladas para gerar a imagem final, o processamento dos dados radiométricos foi realizado via software QGIS 2.18.3 e são descritos a seguir.

\subsubsection{Temperatura de Superficie Terrestre (TST)}

O produto MOD11 do sensor MODIS, é uma das variáveis fundamentais para se descrever os processos da superfície terrestre, sendo extremamente requisitados para diversos estudos climáticos, hidrológicos, ecológicos e biológicos (Running et al., 1994 e Warren et al., 2012). Cita-se, como exemplo de processos hidrológicos, a evapotranspiração, que é altamente sensível às flutuações da TST. O algoritmo Land Surface Temperature (LST) é utilizado para recompor pixels com emissividades conhecidas nas bandas 31 e 32 . A base física dia /noite do algoritmo LST é utilizada simultaneamente para recompor bandas de emissividade e temperatura junto com dados observacionais das bandas 20 a 23 e 31 a 33 sobre todos os tipos de cobertura terrestre (Santos et al., 2020). 

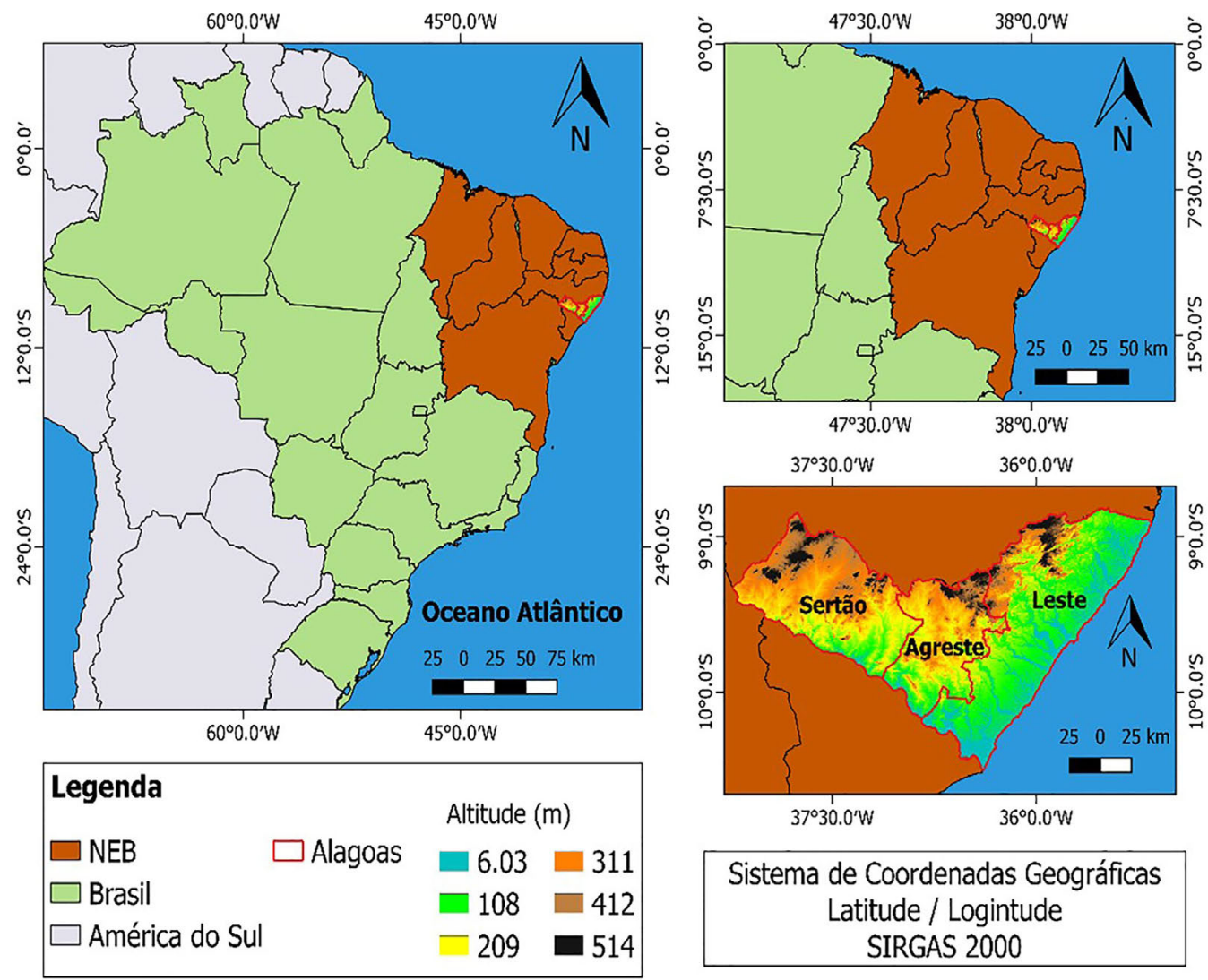

Figura 1 - Localização da área de estudo em destaque o Estado de Alagoas e suas mesorregiões climáticas (Leste, Agreste e Sertão Alagoano), distribuição de altitude (m).

Através do programa MODIS Reprojection Tool (MRT), as imagens MOD11A1 foram convertidas da projeção sinusoidal para a projeção UTM 22S, Datum WGS 1984, e do formato Hierarchical Data Format (HDF) para o formato Tagged Image File Format (TIF). Os níveis de cinza do produto MOD11A1 foram convertidos em LST ou TST $\left({ }^{\circ} \mathrm{C}\right)$, calculada através da Eq. (1):

$$
\operatorname{TST}\left({ }^{\circ} \mathrm{C}\right)=(B 1 \times 0.02)-273,15
$$

em que TST $\left({ }^{\circ} \mathrm{C}\right)=$ Temperatura em Graus Celsius, $B 1=$ Valor original do pixel no produto MOD11A1 e $0.02=$ Fator de conversão (Scale Factor).

\subsection{1. Índice de vegetação por diferença normalizada (IVDN)}

A fim de estabelecer um comparativo entre as áreas de diferentes coberturas vegetais para os anos de $2001 \mathrm{e}$ 2016, utilizou-se o IVDN. Tal índice é uma relação entre medidas espectrais (reflectância $-r$ ) de duas bandas, a do infravermelho próximo (800-1100 nm) e a do vermelho (600-700 nm). O IVDN visa eliminar diferenças sazonais do ângulo do Sol e minimizar os efeitos da atenuação atmosférica Huete et al. (2002). Os valores obtidos com o IVDN variam, entre $-1 \mathrm{e}+1$, ele é calculado através da Eq. (2):

$$
I V D N=(\rho I V P-\rho V) /(\rho I V P+\rho V)
$$

em que IVP representa a refletância no infravermelho próximo; $V$, a refletância no vermelho. Uma peculiaridade atribuída ao $I V D N$ é a rápida saturação, o que o torna insensível ao aumento da biomassa vegetal a partir de determinado estágio de desenvolvimento (Santos et al., 2020).

Para melhor compreensão dos resultados obtidos para o IVDN, foi realizada a classificação do índice de acordo com o uso e ocupação do solo do Estado de Alagoas através do produto de dados MCD12Q1 Versão 6 do sensor MODIS Terra e Aqua. De acordo com SullaMenashe e Friedl (2019) esse produto incorpora cinco tipos diferentes de esquema de classificação de uso do solo com resolução espacial de $500 \mathrm{~m}$. Segundo Friedl (2002, 2010) o produto MCD12Q1 é criado usando classificação supervisionada da reflectância. O tipo de classificação selecionada para a realização desse trabalho foi o Land Cover Property 2. Ainda para melhor compreender os resultados de IVDN, eles foram analisados e comparados entres os anos estudados, dessa maneira, foi possível observar como o índice se distribui ao longo do território alagoano. 


\section{Resultados e Discussão}

\section{1. Índice de Vegetação por Diferença Normalizada (IVDN)}

Os dados de uso do solo foram obtidos a partir do produto MCD12Q1 do MODIS, a Tabela 1 apresenta o Sistema de Classificação da Cobertura da Food and Agriculture Organization (FAO) adaptados de Di Gregorio (2005) e Sulla-Menashe et al. (2011). Cada classe de uso de solo possuem um valor atribuído aos pixels que a compõe (Fig. 2).

Os menores valores de IVDN foram observados para corpos d'água (valores negativos), para áreas de solo exposto, com variações entre 0,1 e 0,26 . Tais resultados corroboram com os valores encontrados por Alves et al. (2015) e Gomes et al. (2012) que encontraram valores negativos, entre -1 a 0 para corpos d'água na Microrregião do Sertão do São Francisco Alagoano e valores entre 0.09

Tabela 1 - Valores espaciais das classes do Índice de Vegetação por Diferença Normalizada (IVDN).

\begin{tabular}{lcc}
\hline Classes & $\begin{array}{c}\text { Valores de } \\
\text { IVDN }\end{array}$ & Autores \\
\hline Corpos d'água & $<0,1$ & Gomes et al. (2012) \\
Solo exposto & $0,1-0,26$ & Salis et al. (2017) \\
$\begin{array}{l}\text { Vegetação rala (arbustos e gramí- } \\
\text { neos) }\end{array}$ & $0,26-0,43$ & $\begin{array}{c}\text { Aquino e Oliveira } \\
(2012)\end{array}$ \\
$\begin{array}{l}\text { Vegetação esparsa (vegetação de } \\
\text { porte médio) }\end{array}$ & $0,43-0,59$ & Lima et al. (2013) \\
$\begin{array}{l}\text { Vegetação densa (vegetação } \\
\text { ombrófila) }\end{array}$ & $>0,59$ & $\begin{array}{c}\text { Fausto (2014); } \\
\text { Arruda (2015) }\end{array}$ \\
\hline
\end{tabular}

e 0.25 para solo exposto para no munícipio de Água Branca - AL.

Em áreas de Vegetação Rala (baixa densidade vegetativa), caracterizadas por arbustos e gramíneas, foram encontrados valores que variam entre 0,26 e 0,43 . Aquino e Oliveira (2012) obtiveram valores entre 0,2 e 0,4 em regiões de vegetação rala, em seu estudo de avaliação dos padrões espaciais e temporais de variabilidade do IVDN do Núcleo de São Raimundo Nonato, Piauí, nas escalas interanual e sazonal.

De acordo com a Tabela 1 os valores de IVDN ficaram entre 0,43 a 0,59 para Vegetação Esparsa, que apresenta valores superiores aos encontrados por Lima et al. (2013), que estimaram para áreas com vegetação esparsa/ degradada valores de IVDN variando entre 0,46 a 0,55 .

Os valores de IVDN foram superiores a 0,59 (Tabela 1) indicam áreas com maior vigor e densidade vegetativa (vegetação ombrófila). Tais resultados estão de acordo com os encontrados por Fausto (2014), que encontrou valores de IVDN entre 0,65 a 0,79 para áreas de Mata Ciliar na Bacia do Alto do Rio Paraguai. Arruda (2015), que verificou em áreas com maiores índices vegetativos (vegetação densa) valores de IVDN superior a 0,52 podendo chegar a 0,72 para o município de Cuiabá - MT. Alves et al. (2015), que observou que em regiões de maior vigor vegetativo, vegetação de porte médio e mata, valores de IVDN superiores a 0,6 .

A distribuição dos dados apresentada conforme a Fig. 3, mostra sua variabilidade em ambos os anos de análise (2001-2016). Entre o IVDN e chuva houve semelhanças nos padrões de comportamento ao longo do período analisado, no entanto, existem grandes variações na dis-
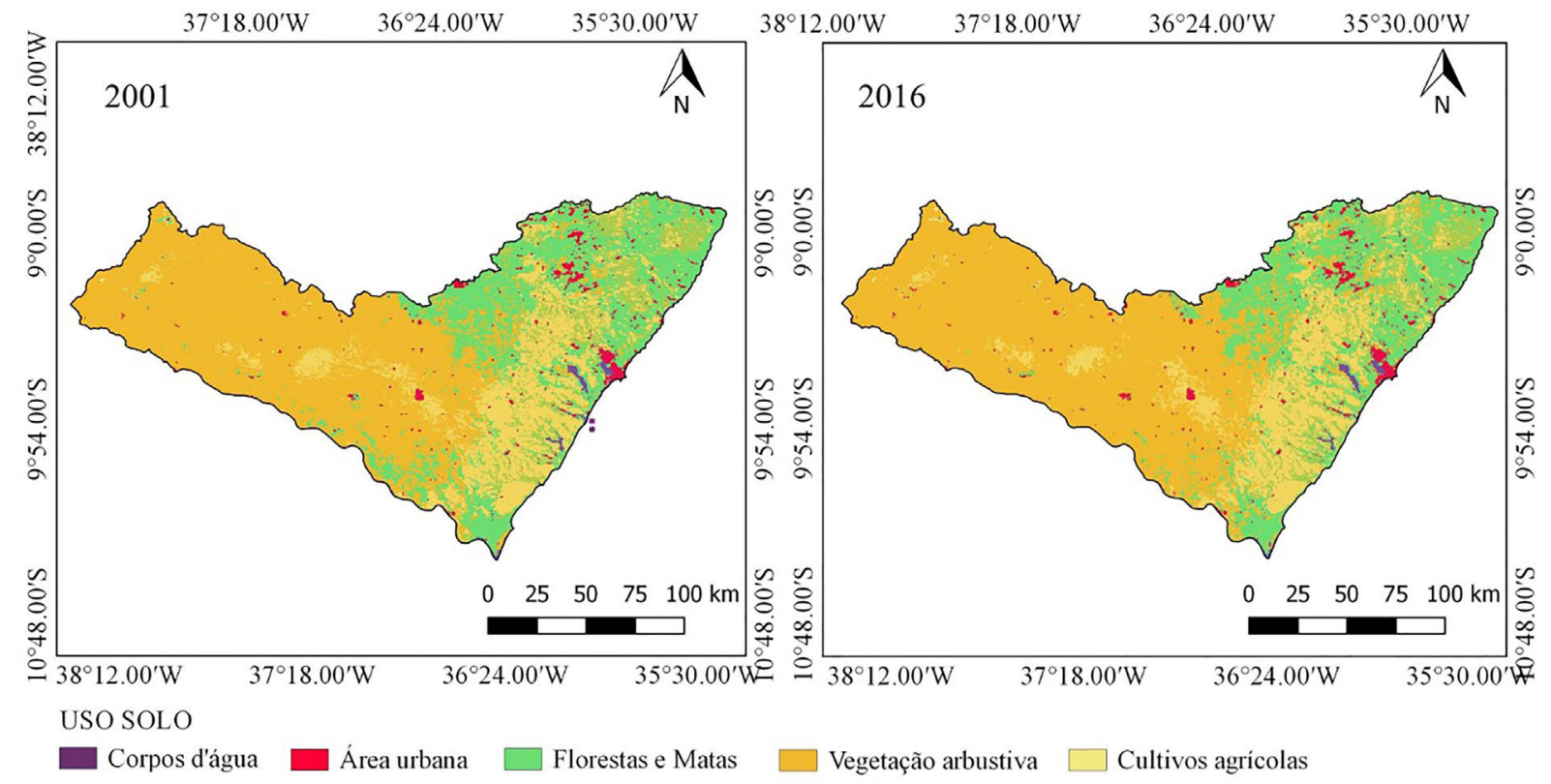

Figura 2 - Mapa de uso e cobertura vegetal do solo para os anos de (2001-2016), Estado de Alagoas. 

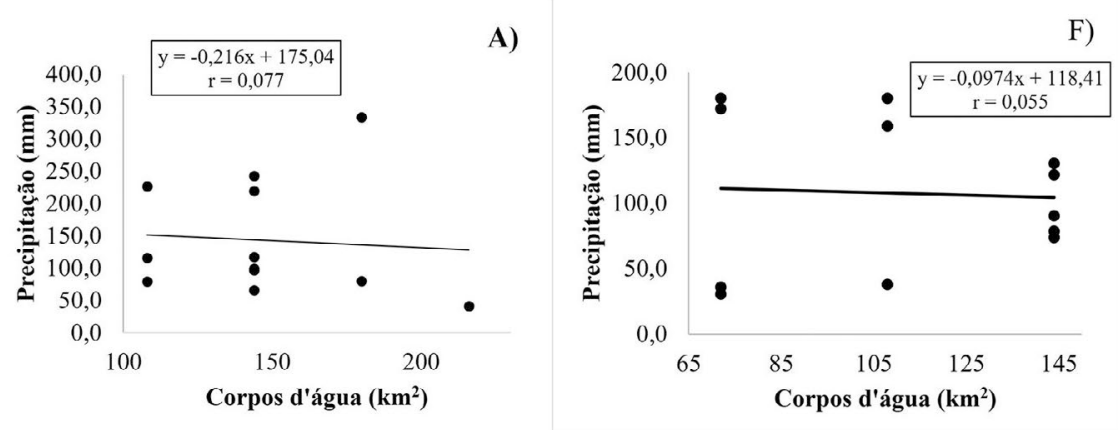

B)
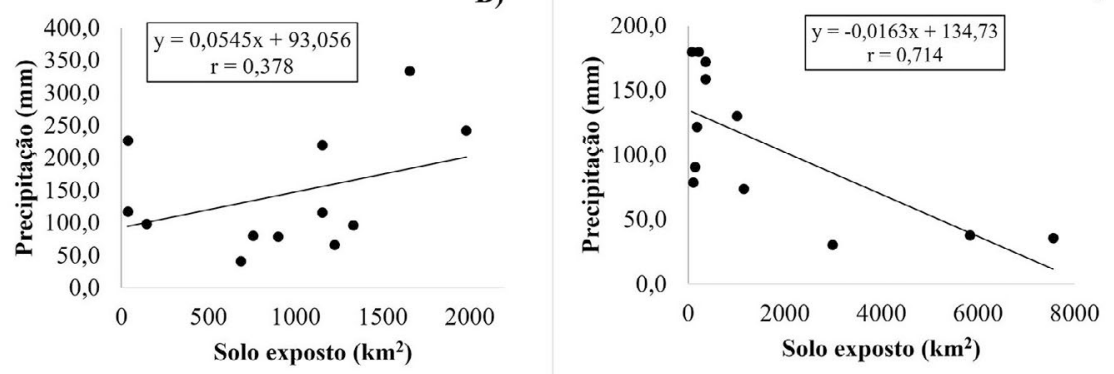

C)

II)
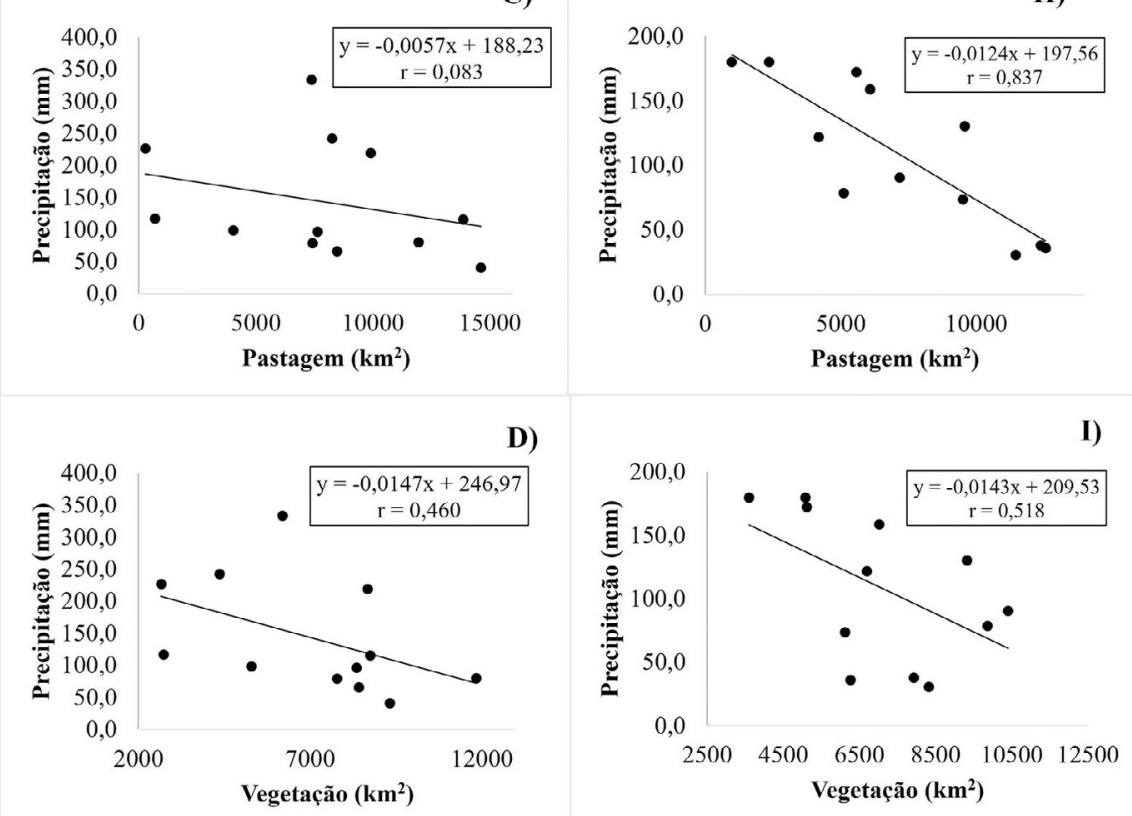

I)
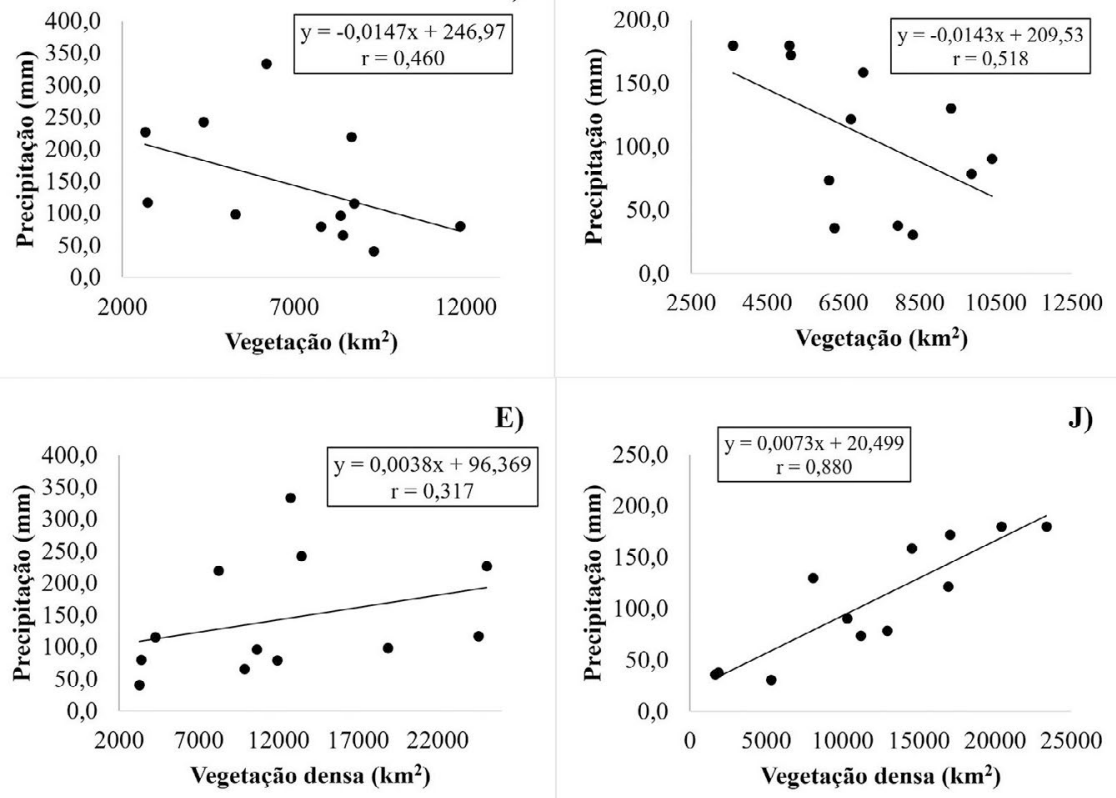

Figura 3 - Correlações entre a precipitação pluviométrica e IVDN (A, B, C, D, E) 2001 e (F, G, H, I, J) 2016 para o estado de Alagoas. 
persão dos dados, com isso, é válido ressaltar que as correlações contemplam dados de 5 tipos diferentes de classes de uso e ocupação do solo, ao comparar os resultados obtidos do IVDN e chuva, as classes de solo exposto e vegetação densa apresentado os melhores valores para os coeficientes de correlação, é observado uma correlação positiva entre a classe da vegetação densa $(r=0,880)$ e correlação negativa com o solo exposto $(r=0,714)$, logo após os meses com maiores e menores índices pluviométricos, estas evidências corroboram com as afirmações de Correia Filho et al. (2018), que identificaram o maior teor vegetativo entre os meses de outubro a dezembro de 2011, Este sistema chega à sua posição mais ao norte do NEB (NNEB) e sul do NEB (SNEB), proveniente das chuvas no período, com valores superiores a 0,5 . O comportamento do IVDN ao longo do ano deve-se principalmente pela distribuição sazonal da chuva no estado de Alagoas, que age de forma intensa no desempenho da fenologia da vegetação (Silva e Santos, 2007). Observa-se também que com a chegada do período mais seco os valores de IVDN começam a diminuir Leivas et al. (2014), respondendo diretamente a distribuição sazonal da precipitação dessa região, Gurgel; Ferreira e Luiz (2013) observaram que na região nordeste do Brasil, mostra um ciclo anual bem definido, com um período seco marcante, sendo que os valores mais elevados de IVDN ocorrem entre os meses de abril e maio, que é o final da época das chuvas, e os menores em setembro e outubro.

A Fig. 4 apresenta uma relação entre a TST e o IVDN, com destaque para as classes vegetação densa e solo exposto. Comparativamente os índices TST e vegetação densa mostraram uma correlação forte negativa $(\mathrm{r}=0,839 \mathrm{e} \mathrm{r}=0,967)$, pois à medida que o vigor vegetativo aumentou a TST começou a diminuir. As áreas de solo exposto têm uma correlação fraca/moderada positiva $(\mathrm{r}=0,339$ e $\mathrm{r}=0,698)$ com a TST, é possível observar que nos primeiros e últimos meses dos anos estudados a relação entre a TST e a classe de solo exposto demonstra uma maior relação comparada aos outros meses do ano.

Santos et al. (2020), observaram maiores variações na série temporal que resultam em uma tendência de aumento da TST ao longo dos 17 anos (2003-2019) de dados observados no estado de Pernambuco, isso pode ser justificado em função dos últimos anos de estiagem prolongada ocorrentes na região, proporcionando uma tendência de redução nos valores de IVDN a partir de 2009 em 2012 foi registrada precipitação em torno de $92 \mathrm{~mm}$. Segundo Santos et al. (2017), entre os anos de 2013 e 2016 os registros de chuva totalizaram em $293 \mathrm{~mm}$, $326 \mathrm{~mm}, 255 \mathrm{~mm}$ e $373 \mathrm{~mm}$, respectivamente.

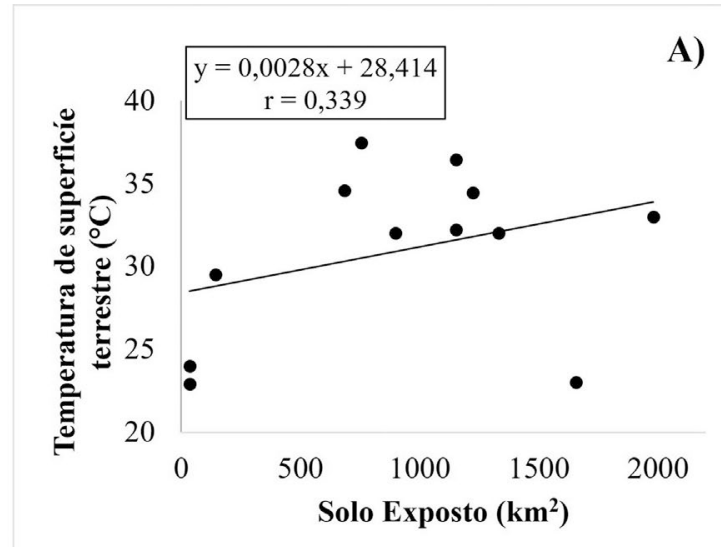

A)

B)

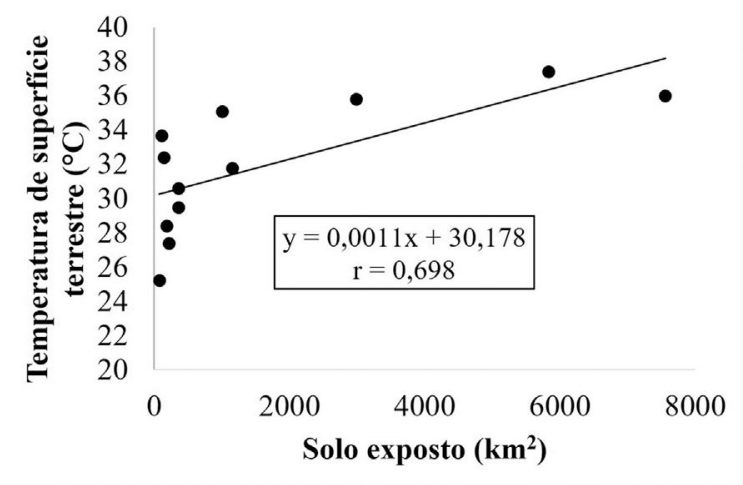

C)
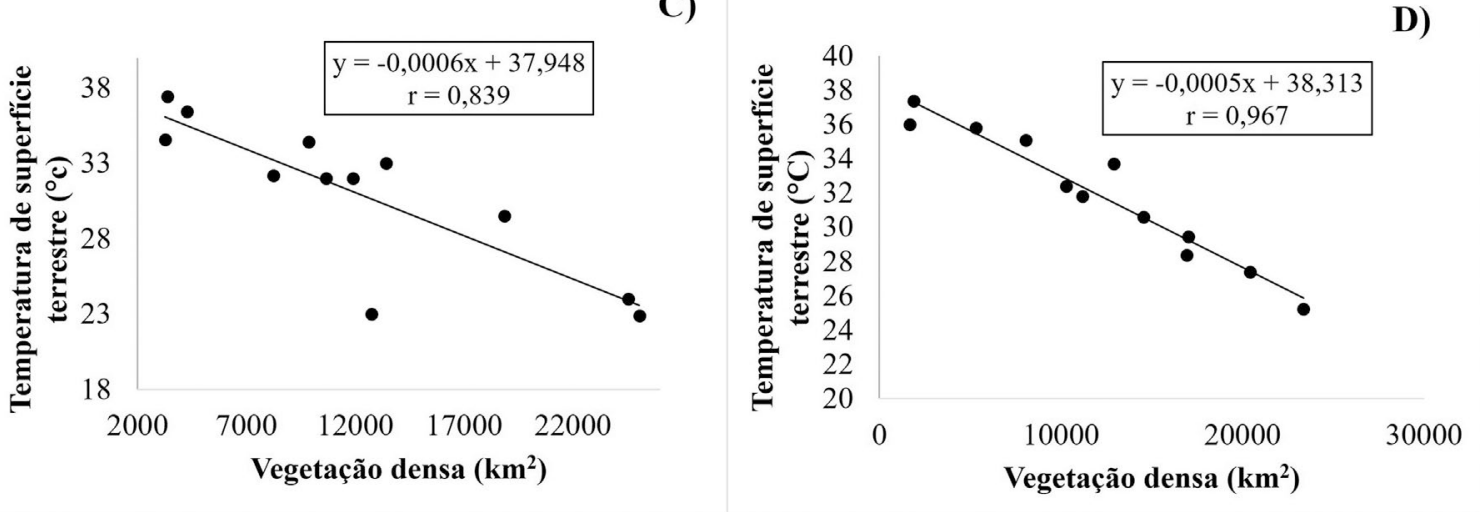

Figura 4 - Correlação entre TST e IVDN, por unidade de área, para o ano de (A, C) 2001 e (B, D) 2016 para o estado de Alagoas. 
As Figs. 5-6 apresentam respectivamente os mapas temáticos do IVDN, obtidos para os anos 2001 e 2016. Durante o período avaliado mostrou similar para grande parte dos meses estudados, com uma diferença tanto no IVDN quanto na TST nos últimos três meses do ano de 2016, onde foram observados valores de TST mais elevados e uma redução no IVDN.

É evidente a influência da época do ano no vigor vegetativo, visto que os totais pluviométricos observados para o estado de Alagoas, apesar de altos, não apresentam uma boa distribuição espacial como observado por Correia Filho et al. (2018) para o NEB. De acordo com Becerra, Shimabukuro e Alvalá (2009), em estudo sobre a relação entre a vegetação e a chuva na região do Cerrado, por meio dos índices de vegetação IVDN e Índice de vegetação realçado (EVI), observaram que uma menor chuva reduz os valores de EVI e IVDN, nas Figs. 5-6 é possível observa a resposta da vegetação para os anos que constituem a quadra chuvosa da região que compreende aos meses de maio, junho, julho e agosto.

Os menores valores encontrados nas imagens estão na mesorregião do Sertão, compreendendo uma vasta área de solo exposto e vegetação rala, em contrapartida os maiores valores correspondem às mesorregiões do Agreste e Leste comportando áreas de vegetação esparsa e densa. As áreas onde se encontram as classes corpos d'água tiveram uma diferença anual de $0,13 \%$, onde o ano de 2001 mostrou valores superiores ao ano de 2016, logo, as áreas de solo exposto tiveram valores maiores no ano de 2016 cerca de 6\% da área total do Estado, enquanto no ano de 2001 o total para mesma área foi $3 \%$, a diferença mais significativa ocorreu nos últimos três meses do ano, onde a soma dos meses de outubro, novembro e dezembro tiveram apenas $6 \%$ do o ano total anual de IVDN para o Estado.

A Fig. 7 mostra as mudanças ocorridas na cobertura vegetal entre os anos de 2001 e 2016, valores positivos indicam maior ganho de IVDN e, inversamente, valores negativos indicam decréscimo no IVDN do ano de 2016. Logo, os valores intermediários próximos a zero representam pouca variação do índice entre os anos analisados, esses valores se explicam devido ao baixo índice pluviométrico que ocasionou essa redução do índice, como mostra Becerra, De carvalho e Ometto (2015), que verificaram maiores picos de IVDN em áreas com maior teor de umidade e densidade vegetativa. Já Lopes et al. (2010) verificaram a influência da chuva na resposta do IVDN, que de acordo com a nutrição da planta (saudável), tendo em vista

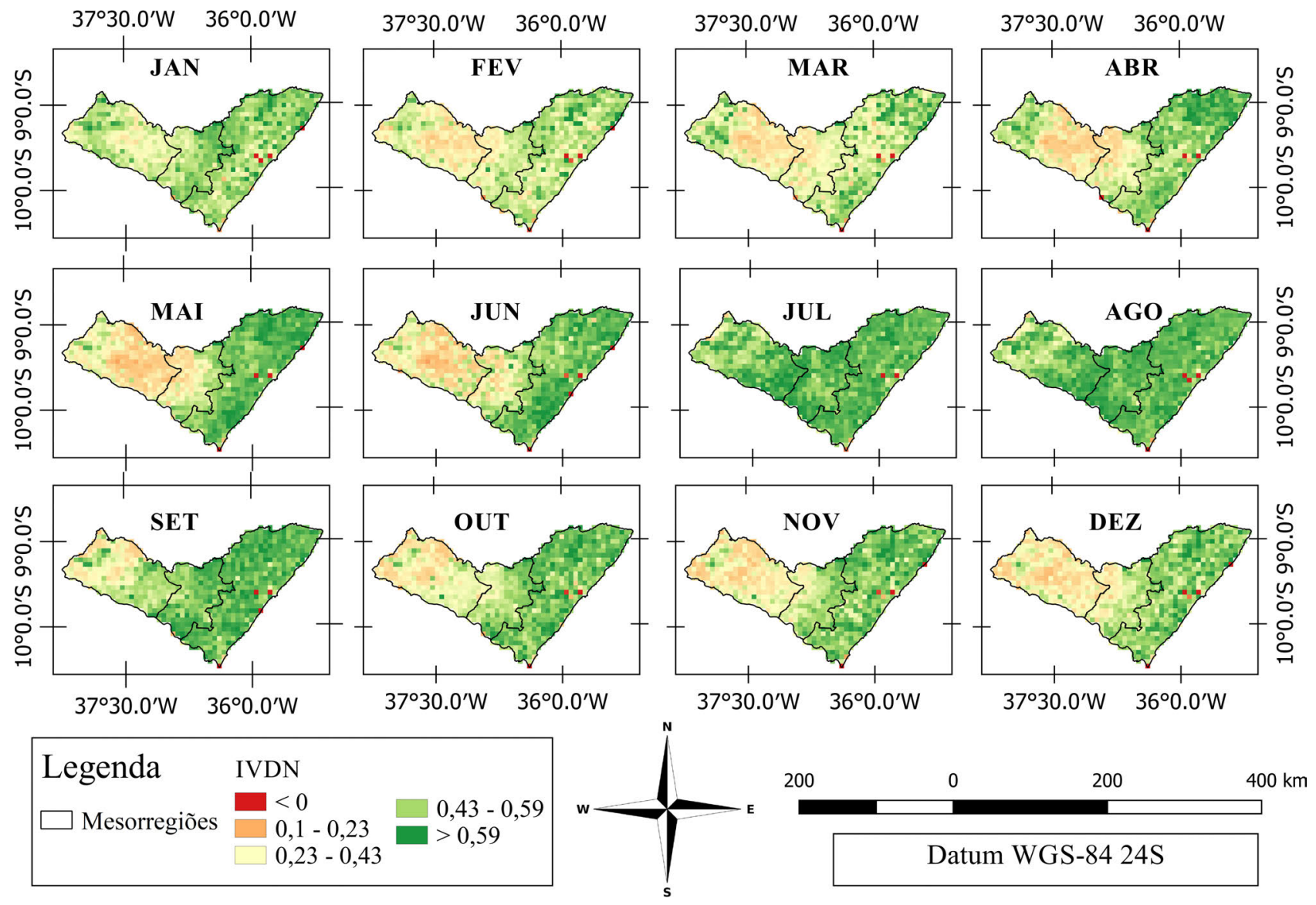

Figura 5 - IVDN mensal para 2001. 


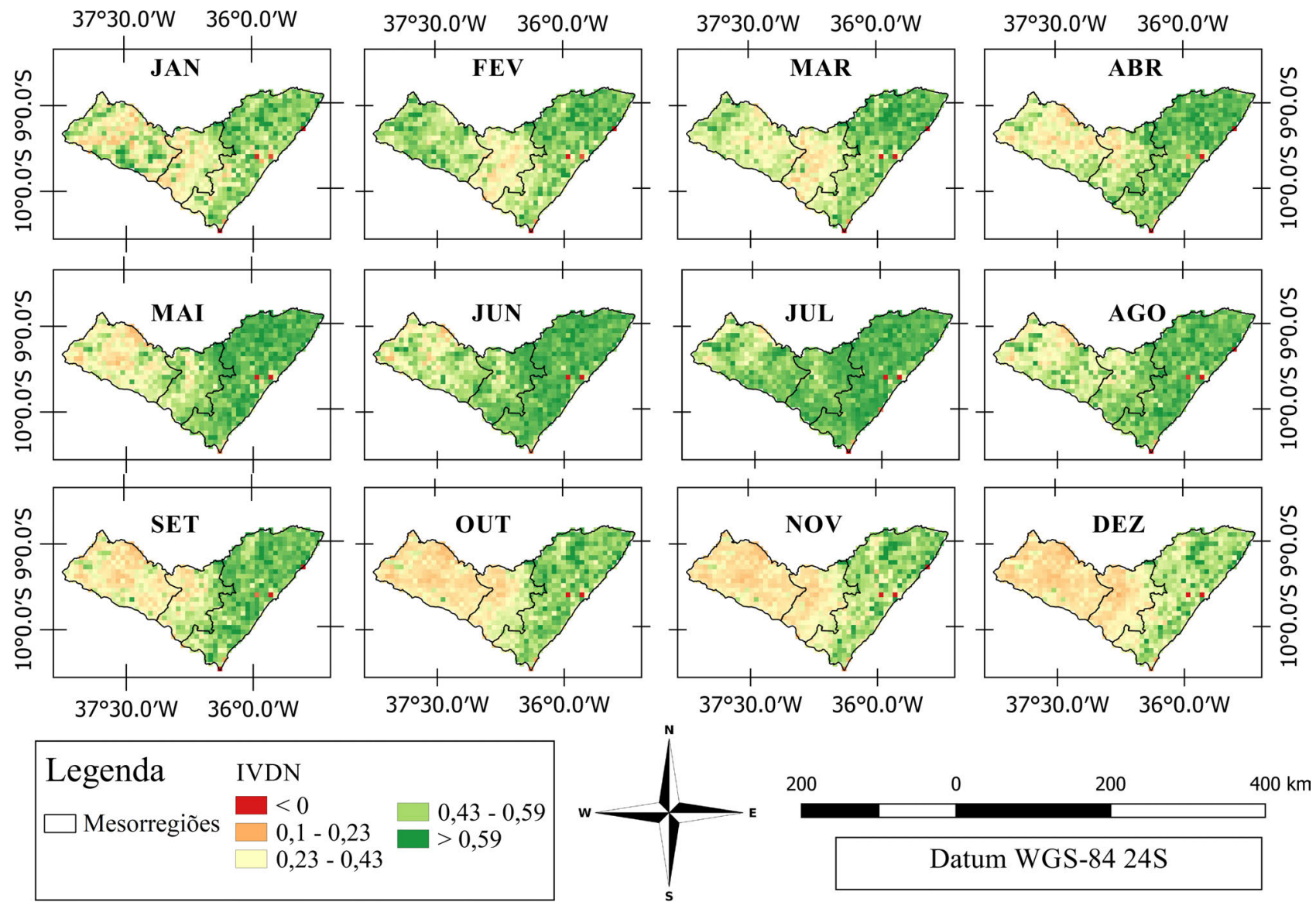

Figura 6 - IVDN mensal para 2016.

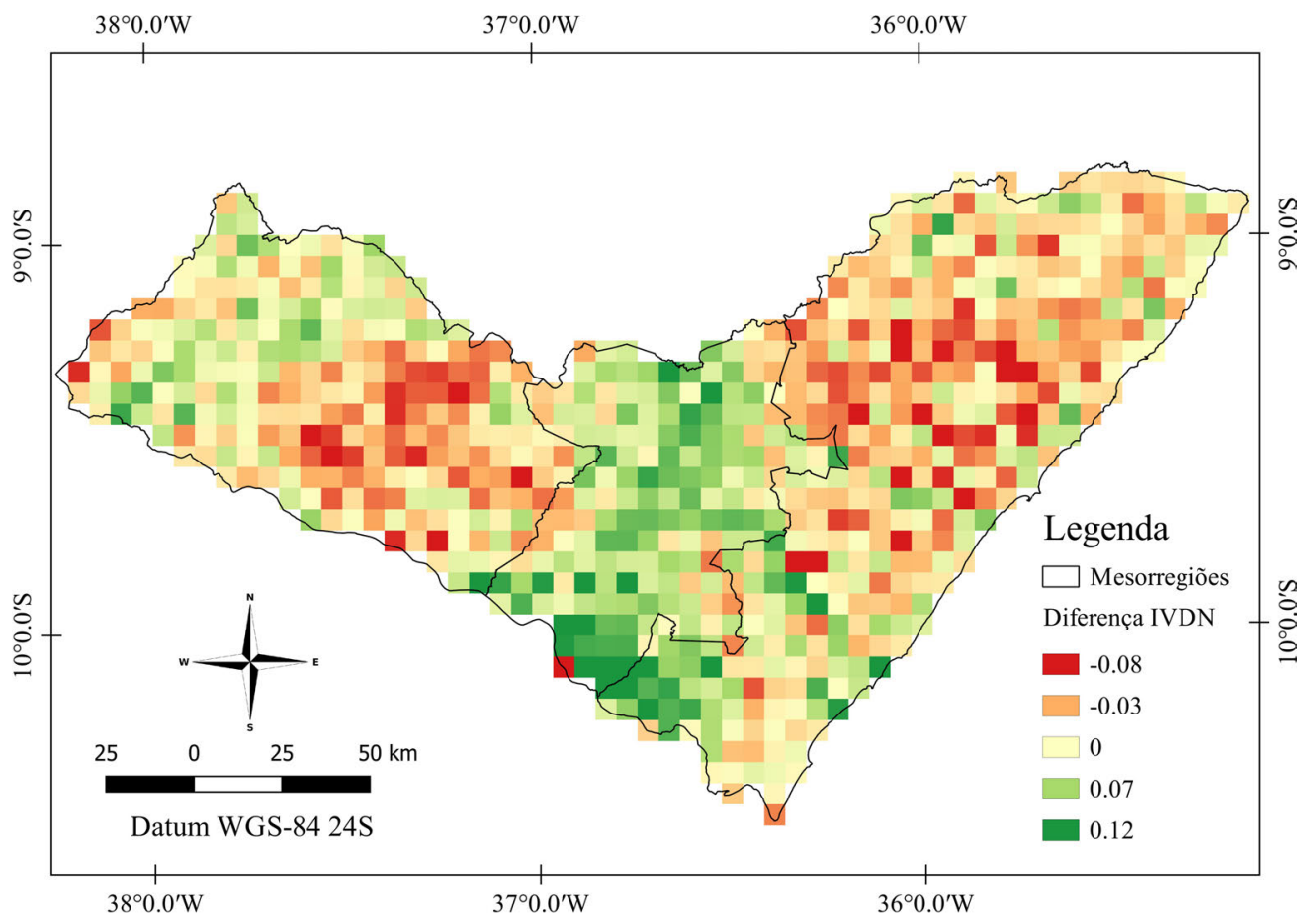

Figura 7 - Diferença de IVDN entre os anos de 2001 e 2016 em Alagoas. 
que suas necessidades hídricas estão sendo supridas devida a chuva local.

\subsection{Precipitação}

No período chuvoso há uma maior representatividade no total pluviométrico anual, o período chuvoso de 2001 foi de $(673,5 \mathrm{~mm})$, enquanto no período seco $(365,3)$. Já o ano de 2016 apresentou valores menores para o período chuvoso $(511,1 \mathrm{~mm})$, e valores bem abaixo para o período seco $(104,6 \mathrm{~mm})$. Dessa forma, possibilitar a separação do parâmetro chuva, como principal elemento que causa o aumento ou redução da vegetação, visto que podem ter outros fatores, como aumento de área agrícola, urbanização entre outros parâmetros. Após as análises com base na (tabela 2), conclui-se que os meses de abril, maio e junho é o período chuvoso da região de estudo, o estado tem o regime diferenciado na parte norte, com chuvas máximas no trimestre fevereiro, março e abril, já na parte do sul possui chuvas máximas no trimestre novembro, dezembro e janeiro, e em grande parte do agreste e litoral (leste) os maiores índices pluviométricos são observados no trimestre maio, junho e julho. Barros et al. (2012).

De acordo com Barros et al. (2012), alguns sistemas tem papel fundamental no regime de chuvas no estado e estão diretamente relacionados com as configurações da circulação atmosférica e oceânica em grande escala sobre os trópicos, dentre os quais destacam-se a Zona de Convergência Intertropical (ZCIT); os Sistemas Frontais (SF), alimentados pela umidade do Atlântico Sul, proximidade das bordas do Vórtice Ciclônico de Altos Níveis (VCAN), Ondas de Leste que são agrupamentos de nuvens que se movem no Atlântico de leste para oeste e dos Ventos Alísios de Nordeste e Sudeste (Marengo et al., 2016; Kouadio et al., 2010).

O ano de 2001 não mostra uma grande diferença de chuva para o primeiro trimestre com relação ao ano de 2016, de modo geral, a maior discrepância entre os valores de precipitação foi observada no último trimestre o teste-t nos permite afirmar que houve uma diferença na média dos valores nos totais pluviométricos dessa região como demonstra a Tabela 2 .

A diminuição da chuva no último trimestre do ano de 2016, está relacionada ao modo de variabilidade climá- tica ENOS, que ocasiona mudanças na TSM do Pacífico tropical mais quente (El Niño) ou mais frio (La Niña) do que a média normal histórica, podem afetar diretamente a chuva sobre o NEB através de mudanças na circulação Walker orientada zonalmente (Ambrizzi et al., 2004). A Fig. 8 mostra o desvio de precipitação trimestral para os meses de outubro, novembro e dezembro, onde, é possível verificar a anomalia observada nas imagens estudadas de precipitação para o último trimestre do ano de 2016.

\subsection{Temperatura da Superfície Terrestre (TST)}

A (Tabela 3) apresenta os valores máximo, médio e mínimo extraídos das imagens geradas para os respectivos anos de estudo. O menor valor de TST para o ano de 2001

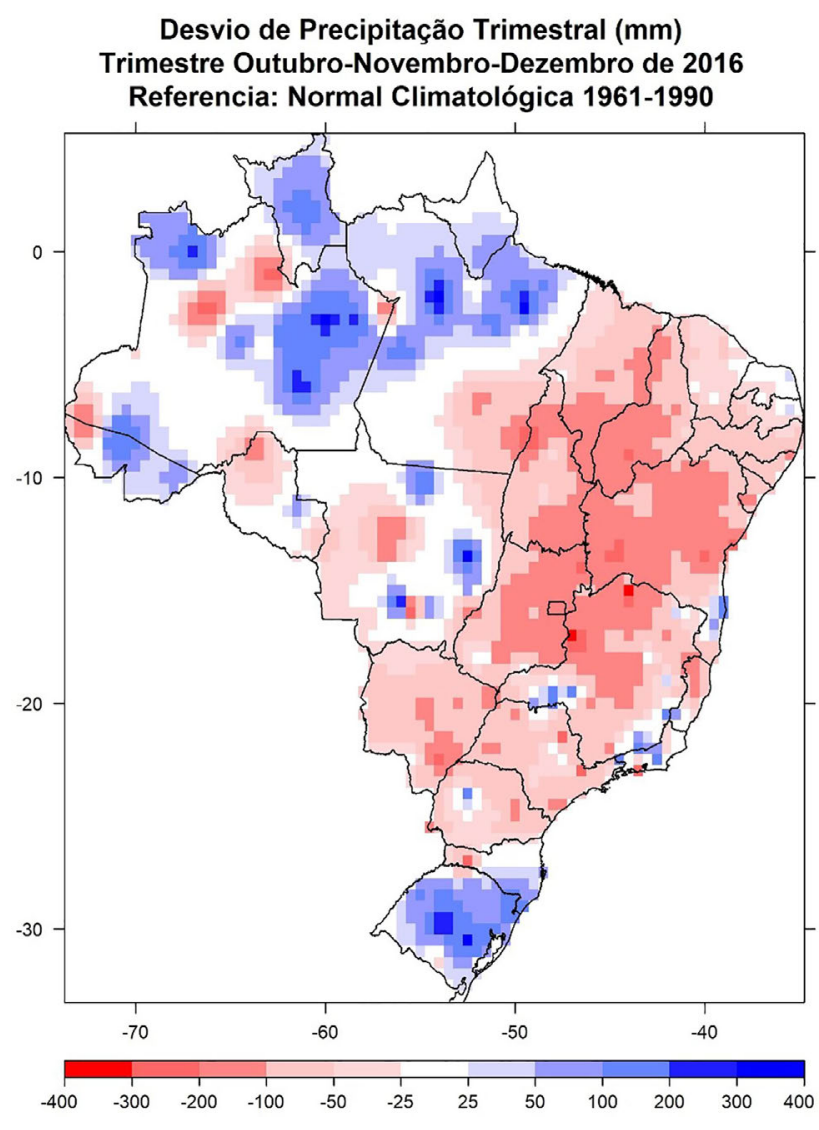

Figura 8 - Desvio de precipitação trimestral para o ano de 2016. Fonte: INMET, 2016.

Tabela 2 - Valores espaciais das classes do Índice de Vegetação por Diferença Normalizada (IVDN).

\begin{tabular}{|c|c|c|c|c|c|c|}
\hline \multirow[t]{2}{*}{ Trimestres } & \multicolumn{3}{|c|}{ Chuva (mm) } & \multirow[t]{2}{*}{ Teste- $t$} & \multirow[t]{2}{*}{ Desvio padrão (2001) } & \multirow[t]{2}{*}{ Desvio padrão (2016) } \\
\hline & 2001 & 2016 & Climatologia & & & \\
\hline JFM & 237,2 & 299,7 & 172,6 & 0,240 & 37,51 & 27,04 \\
\hline AMJ & 673,5 & 511,2 & 491,56 & 0,239 & 119,62 & 10,71 \\
\hline JAS & 443,3 & 375,7 & 331,6 & 0,339 & 69,62 & 53,16 \\
\hline OND & 365,3 & 104,7 & 101,36 & 0,048 & 85,023 & 3,79 \\
\hline
\end{tabular}


Tabela 3 - Valores máximos, mínimos e médios da TST $\left({ }^{\circ} \mathrm{C}\right)$ para o estado de Alagoas para os anos de estudo 2001 e 2016.

\begin{tabular}{ccccccc}
\hline Mês/ano & \multicolumn{3}{c}{2001} & & & 2016 \\
\cline { 2 - 7 } & MAX & MIN & MED & MAX & MIN & MED \\
\hline JAN & 42,4 & 28,8 & 34,6 & 47,9 & 28,6 & 35,1 \\
FEV & 45,0 & 31,1 & 37,5 & 46,5 & 27,6 & 33,7 \\
MAR & 44,0 & 29,2 & 36,4 & 41,6 & 26,8 & 32,4 \\
ABR & 40,0 & 26,6 & 32,0 & 40,6 & 25,9 & 30,6 \\
MAI & 40,6 & 26,7 & 33,0 & 38,6 & 24,5 & 29,5 \\
JUN & 33,9 & 22,0 & 23,0 & 36,5 & 23,8 & 27,4 \\
JUL & 31,0 & 21,5 & 22,9 & 32,0 & 23,1 & 25,2 \\
AGO & 32,0 & 22,5 & 24,0 & 37,3 & 24,6 & 28,4 \\
SET & 40,5 & 24,8 & 29,5 & 43,1 & 25,7 & 31,8 \\
OUT & 44,0 & 26,7 & 32,0 & 46,4 & 28,8 & 35,8 \\
NOV & 47,1 & 27,9 & 34,4 & 47,5 & 28,6 & 37,4 \\
DEZ & 43,2 & 25,8 & 32,2 & 47,8 & 29,0 & 36,0 \\
\hline & & & & & &
\end{tabular}

foi de $21,5^{\circ} \mathrm{C}$ para o mês de julho e seu maior valor foi verificado em novembro $\left(47,1^{\circ} \mathrm{C}\right)$, o mês com a média mais elevada foi fevereiro $\left(37,5^{\circ} \mathrm{C}\right)$. Já o ano de 2016 teve seu maior valor no mês de janeiro $\left(47,9^{\circ} \mathrm{C}\right)$, seu valor médio mais elevado foi $\left(37,4{ }^{\circ} \mathrm{C}\right)$ para o mês de novem- bro, já seu menor valor foi observado no mês de julho $\left(23,1^{\circ} \mathrm{C}\right)$, essa diferença ocorreu devido a influência de um forte período de estiagem que ocorreu no final de 2016, elevando os valores de TST dessa região.

$\mathrm{Na}$ avaliação da TST Figs. 9-10, mostrou a influência do período chuvoso para TST, que por sua vez afetou todas as áreas do estado, pois a temperatura apresenta os maiores valores de TST sempre que ocorrem menores índices pluviométricos. Segundo Quadro et al. (1996), grande parte do NEB também possui uma grande homogeneidade sazonal e espacial da TST. No estudo de Oliveira et al. (2012) realizado para Bacia Hidrográfica do Rio Tapacurá, sub bacia do Rio Capibaribe, PE, integrante da Rede de Hidrologia do Semiárido (REHISA) observouse que no período chuvoso da região os valores de TST são inferiores ao da estação seca, pois a chuva no período analisado favoreceu a diminuição da TST. Devido às possíveis alterações antrópicas ao longo desses vários anos de 2001 a 2016. Vamos encontrar diferença nas áreas de cobertura vegetal. Isso ocorre devido aumento das construções de cidades, estradas e pela substituição das áreas vegetadas por cultivo e agriculturas. Tal cenário influencia diretamente para alterar a perda de energia e a transformação de calor sensível em calor latente nas regiões, assim, alterando a evaporação e evapotranspiração, con-

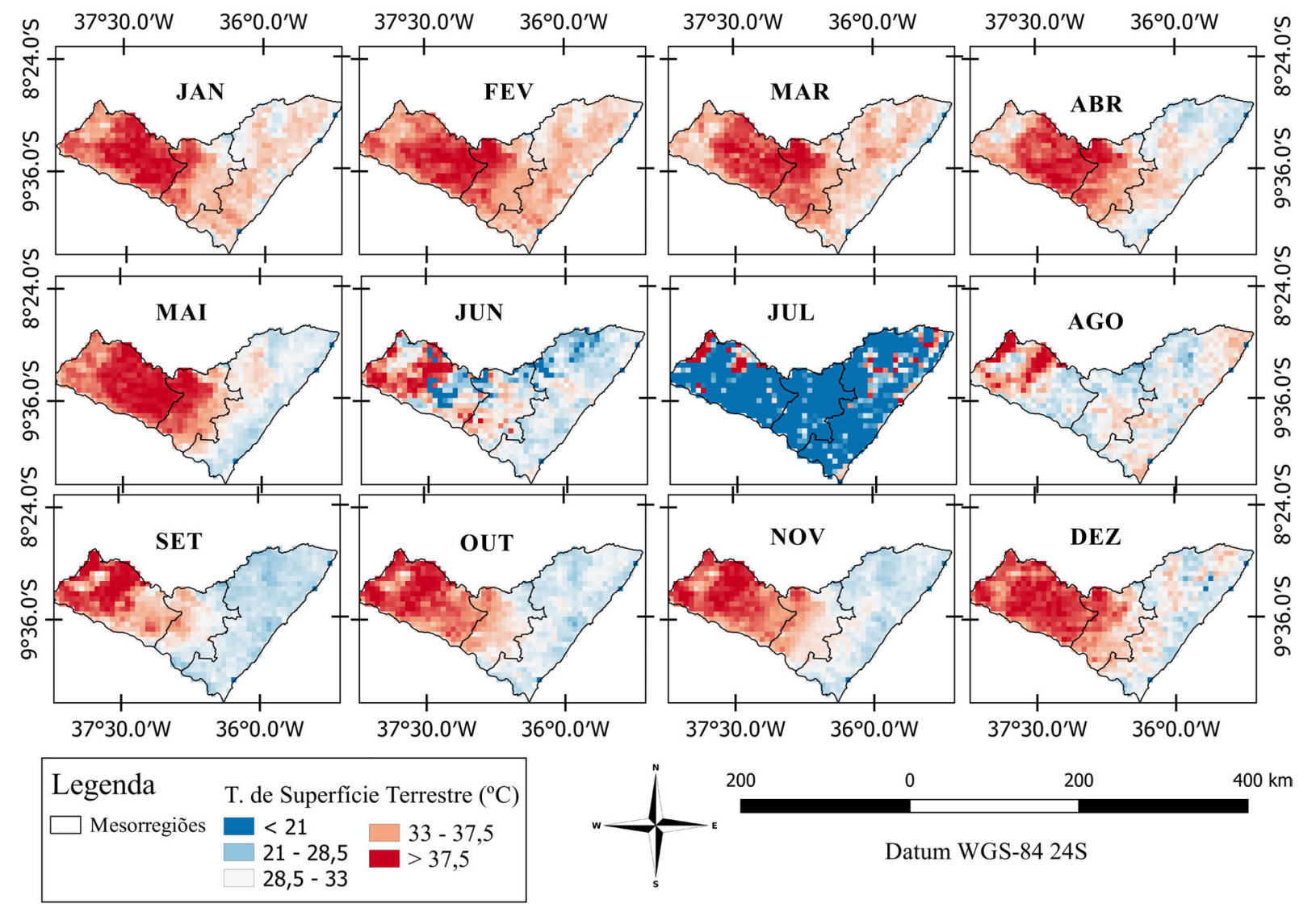

Figura 9 - Temperatura da Superfície (TST) mensal para 2001. 
sequentemente, aumentando a TST das áreas antrópicas Uega Júnior (2013), Santos (2020).

Quando comparados os anos estudados, as mesorregiões leste e sertão Figs. 9-10, mostram o primeiro tri- mestre do ano de 2001 com valores médios da TST superiores ao ano de 2016, enquanto que o ultimo trimestres valores inferiores, na Fig. 11 mostra a diferença entre 2001 e 2016 , onde, os valores positivos representam

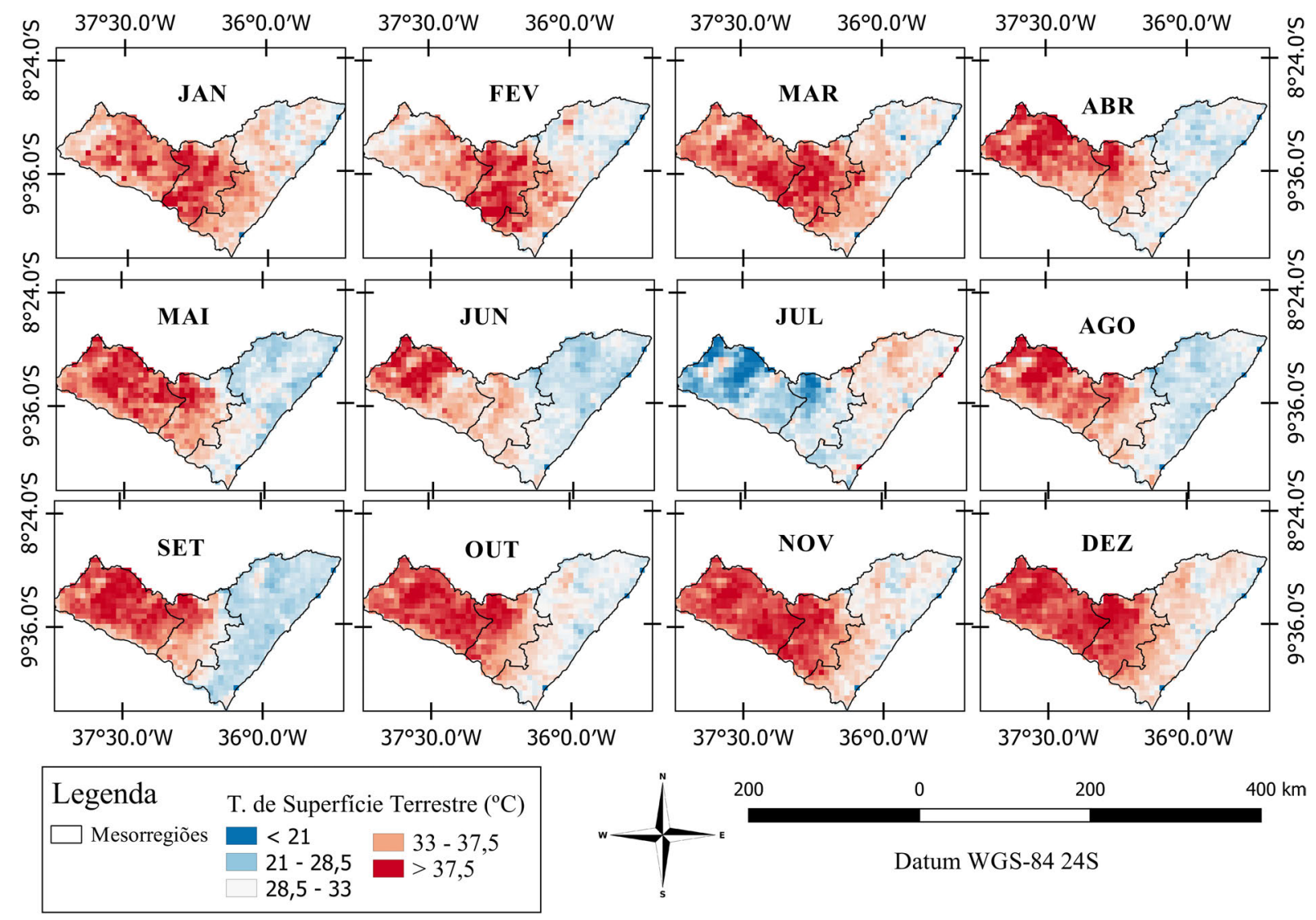

Figura 10 - Temperatura da Superfície (TST) mensal para 2016.

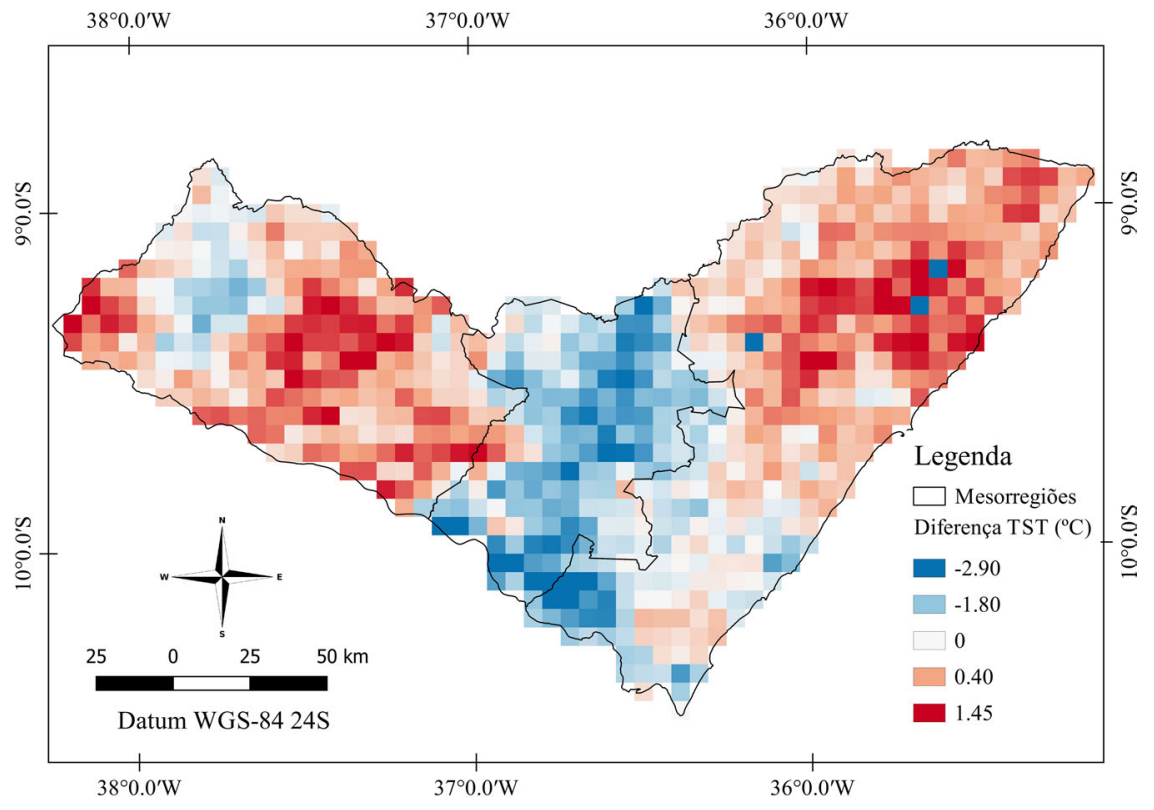

Figura 11 - Diferença da TST $\left({ }^{\circ} \mathrm{C}\right)$ entre os anos de 2001 e 2016 em Alagoas. 
um aumento da TST, e valores negativos uma diminuição, ficando evidente as diferenças observadas Figs. 9-10, entre o primeiro e último trimestre dos anos estudados, de acordo com o Grupo de Estudos Climáticos (2016), os relatório climático mensal dos meses de Outubro, Novembro e Dezembro apresentaram Valores de anômalos de temperatura $(+2.4,+2.1 \mathrm{e}+1.9)$ respectivamente.

A anomalia na Precipitação está ligada diretamente com o aumento da temperatura de superfície, o último trimestre do ano de 2016 apresentou valor de TST média superior ao ano de 2001 , cerca de $\left(3,5^{\circ} \mathrm{C}\right)$ mais quente quando comparado com o mesmo período. Um fenômeno que influencia bastante esta região estudada é o ENOS que afeta o tempo e o clima globalmente, principalmente nos trópicos. Normalmente, é esperado que as chuvas nordestinas sejam igualmente afetadas pelo fenômeno Nobre e Molion (1988). O último trimestre do ano de 2016 apresentou valores superiores ao ano de 2001, comparando com os outros índices estudados, além dos fortes gradientes do litoral ao continente e de norte a sul devido à fisiografia da região Lyra et al. (2014), nota-se uma anomalia de precipitação nesse período de tempo, a Fig. 12 apresenta uma anomalia de temperatura para Ala-

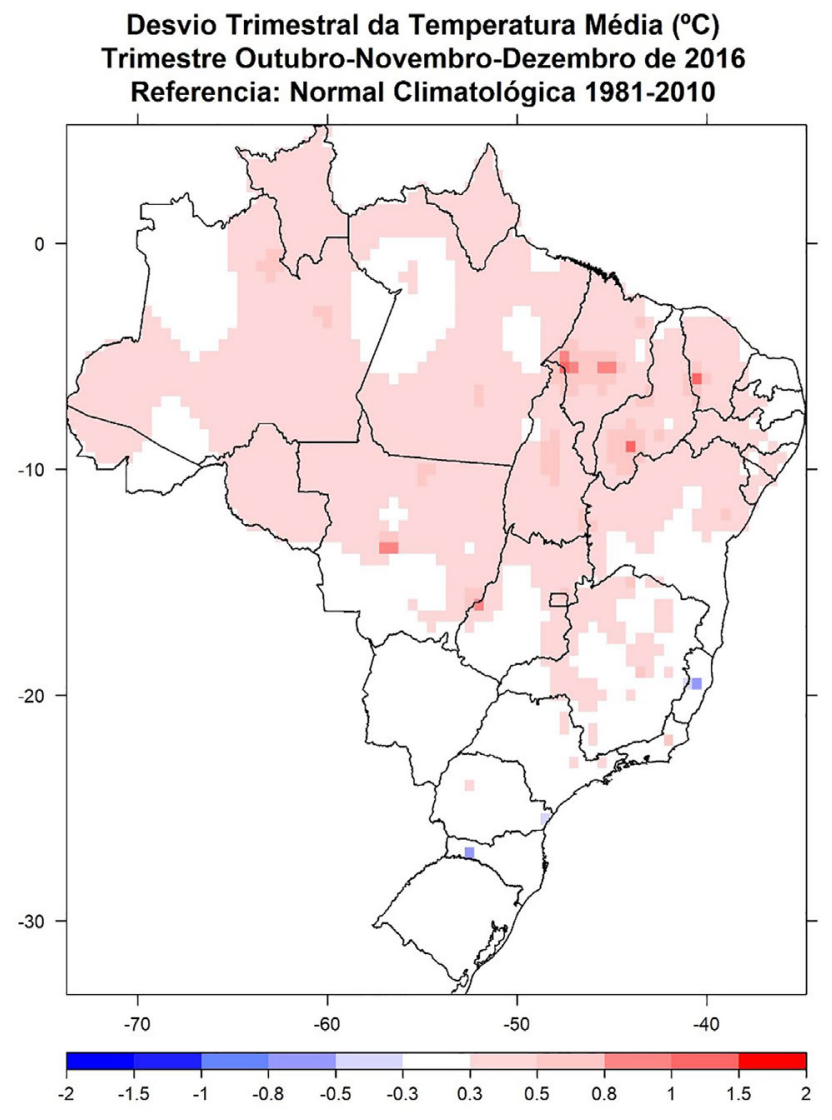

Figura 12 - Anomalias de temperaturas médias para os meses de outubro, novembro e dezembro, correspondente ao ano de 2016. Fonte: INMET, 2016. goas, explicando os maiores valores observados nas imagens processadas, um amento significativo de $\left(4,5{ }^{\circ} \mathrm{C}\right)$ com relação a média climática da região e $\left(3,5^{\circ} \mathrm{C}\right) \mathrm{em}$ relação ao ano de 2001.

\section{Considerações Finais}

A utilização das imagens do sensor MODIS apresenta uma boa aplicabilidade para a avaliação dos parâmetros biofísicos. No estado de Alagoas a distribuição espacial do IVDN, para a classe corpos d'água não possui uma diferença significativa anual. As áreas de solo exposto tiveram valores maiores no ano de 2016. A principal diferença nos resultados ocorre nos últimos três meses do ano, onde 2016 possui baixos valores de IVDN comparado com a mesma época do ano de 2001 para o Estado.

O IVDN é eficiente em comparação aos dados de chuva, principalmente após o início dos registros dos maiores totais pluviométricos. A variabilidade do IVDN ao longo do ano deve-se principalmente pela distribuição sazonal da precipitação no Estado de Alagoas. Já sua relação com TST, quando comparado aos índices, pode-se observar uma relação inversamente proporcional entre a TST e a vegetação densa, já as áreas de solo exposto têm uma correlação direta com a TST.

A distribuição sazonal dos sistemas meteorológicos e a atuação do ENOS sobre os parâmetros biofísicos e da chuva influencia diretamente todo o Estado, pois, cada um dos parâmetros a depender de sua atuação e intensidade, tem a capacidade de alterar as feições dos diversos tipos de cobertura do solo de Alagoas.

\section{Referências}

ALLEN, R.; TASUMI, M.; TREZZA, R. SEBAL (Surface Energy Balance Algorithms for Land)-Advanced Training and User's Manual-Idaho Implementation, Version $1.0,97 \mathrm{p}, 2002$.

AMBRIZZI, T.; DE SOUZA, E.B.; PULWARTY, R.S. The Hadley and Walker regional circulations and associated ENSO impacTST on the South American seasonal rainfall. In: DIAZ; H.F. \& BRADLEY, R.S. (eds). The Hadley Circulation: Present, Past and Future. Kluwer, Dordrecht, p. 203-235, 2004.

ALVES, L.E.R.; GOMES, H.B.; SILVA, E.F.S.; SANTOS, M.N.; SANTOS; C. et al. Mapeamento do IVDN e IVAS para o município de Coqueiro Seco -AL a partir de imagens geradas pelo Thematic Mapper do Landsat 5. In: Lucas Barbosa Cavalcante. (Org.). $3^{\circ}$ GEOALAGOAS - Simpósio sobre geotcnologias e geoinformação do Estado de Alagoas. 3ed.Maceió, v. 1, n. 1, p. 181-188, 2015.

AQUINO, C.M.S.; OLIVEIRA, J.G.B. Estudo da dinâmica do índice de vegetação por diferença normalizada (IVDN) no núcleo de São Raimundo Nonato - PI. Geousp: Espaço e Tempo (Online), v. 16, n. 31, p. 157-168, 2012. 
ARAÚJO, T.L.; DI PACE, F.T. Valores instantâneos da temperatura da superfície terrestre na cidade de Maceió-AL utilizando imagens do satélite TM/Landast 5. Revista Brasileira de Geografia Física, v. 3, n. 2, p. 104-111, 2010.

ARRUDA, A.G.R. Análise de Parâmetros Biofísicos por Sensoriamento Remoto em Diferentes Uso e Ocupação no Município de Cuiabá - MT. Dissertação de Mestrado em Ciências Ambientais, Universidade de Cuiabá, Cuiabá, 85 p., 2015.

BARROS, A.H.C., DE ARAUJO FILHO, J.C., DA SILVA, A.B. SANTIAGO, G.A.C.F. Climatologia do estado de Alagoas. Embrapa Solos-Boletim de Pesquisa e Desenvolvimento (INFOTECA-E), 2012.

BECERRA, J.A.B.; SHIMABUKURO, Y.E.; ALVALÁ, R.C.S. Relação do padrão sazonal da vegetação com a precipitação na região de Cerrado da Amazônia Legal, usando índices espectrais de vegetação. Revista Brasileira de Meteorologia, v. 24, n. 2, p. 125-134, 2009.

CORREIA FILHO, W.L.F.; DOS SANTOS, T.V.; DIOGO, A.M.; DE AMORIM, R.F.C. Diagnóstico da Precipitação e EVI em Dois Eventos de Seca no Nordeste do Brasil. Revista do Departamento de Geografia, v. 35, n. 1, p. 102-112, 2018.

DI GREGORIO, A. Land Cover Classification System: Classification Concepts and User Manual: LCCS. Number 8. Italy: Food \& Agriculture Organization, 2005.

FAUSTO, M.A. Análise de Parâmetros Biofísicos Estimados Pelo Algoritmo SEBAL em Áreas de Cerrado na Bacia do Alto Rio Paraguai. Dissertação de Mestre em Física Ambiental, Universidade Federal de Mato Grosso, Instituto de Física, Cuiabá, 2014.

GOMES, H.B.; SILVA JUNIOR, R.S.; DE PACE, F.T. Mapeamento temático da cobertura vegetal na microrregião do sertão do São Francisco Alagoano, utilizando imagens TM LANDSAT 5. Revista Brasileira de Geografia Física, v. 5, n. 5, p. 1121-1132, 2013.

GRUPO DE ESTUDOS CLIMÁTICOS. Relatorio Climático Mensal. Monitoramento Climático: Out, Nov e Dez/ 2019. Instituto de Astronomia, Geofísica e Ciências Atmosféricas, Universidade de São Paulo, São Paulo, 2019.

HUETE, A.; DIDAN, K.; MIURA, T.; RODRIGUEZ, E.P.; GAO, X.; FERREIRA, L.G. et al. Overview of the radiometric and biophysical performance of the MODIS vegetation indices. Remote Sens. Environ., v. 83, n. 1-2, p. 195213, 2002.

IBGE. IBGE Indicadores. Estatística da Produção Pecuária. Instituto Brasileiro de Geografia e Estatística, 2016.

JENSEN, J.R.; EPIPHANIO, J.C.N.; JENSEN, J.R. Sensoriamento Remoto do Ambiente: Uma Perspectiva em Recursos Terrestres. EPHIFANIO, J.C. (coord.), São José dos Campos: Parêntese, 598 p., 2009.

KOUADIO, Y.K.; SERVAIN, J.; MACHADO, L.A.T.; LENTINI, A.D. Heavy rainfall episodes in the Eastern Northeast Brazil linked to large-scale ocean-atmosphere conditions in the Tropical Atlantic. Advances in Meteorology, v. 2012, n. 1 p. 1-16, 2012.

LEIVAS, J.F.; ANDRADE, R.G.; VICTORIA, D.C.; TORRESAN, F.E.; BOLFE, E.L. et al. Monitoramento da seca 2011/2012 no nordeste brasileiro a partir do satélite spot- vegetation e TRMM. Revista Engenharia Na Agricultura, v. 22, n. 3, p. 211-221, 2014.

LIMA, D.R.O. Diagnóstico de Chuvas e Previsão Meteorológica para a Bacia Hidrográfica do Rio Manso. Dissertação de Mestrado, COPPE/UFRJ, Rio de Janeiro, 2005.

LIMA, G.C.; SILVA, M.L.N.; CURI, N.; SILVA, M.A.D.; OLIVEIRA, A.H.; AVANZI, J.C.; UMMUS, M.E. et al. Avaliação da cobertura vegetal pelo índice de vegetação por diferença normalizada (IVDN). Revista Ambiente \& Água, v. 8, n. 2, p. 204-214, 2013.

LYRA, G.B.; OLIVEIRA-JÚNIOR, J.F.; ZERI, M. Cluster analysis applied to the spatial and temporal variability of monthly rainfall in Alagoas state, Northeast of Brazil. International Journal of Climatology, v. 34, n. 13, p. 3546-3558, 2014.

LYRA, G.B.; ZANETTI, S.S.; SANTOS, A.A.R.; DE SOUZA, J.L.; LYRA, G.B.; OLIVEIRA-JÚNIOR, J.F.; LEMES, M.A.M. et al. Estimation of monthly global solar irradiation using the Hargreaves-Samani model and an artificial neural network for the state of Alagoas in northeastern Brazil. Theoretical and Applied Climatology, v. 125, n. 3-4, p. 743-756, 2015.

MARENGO, J.A.; CUNHA, A.P.; ALVES, L.M. A seca de 2012-15 no semiárido do Nordeste do Brasil no contexto histórico. Climanálise (online), v. 3, n. 1, p. 49-54, 2016.

NASCIMENTO, E.D.L. Previsão de tempestades severas utilizando-se parâmetros convectivos e modelos de mesoescala: uma estratégia operacional adotável no Brasil. Revista Brasileira de Meteorologia, v. 20, n. 1, p. 121-140, 2005.

NOBRE, C.A.; MOLION, L.C.B. The climatology of drought prediction. Impact Clim. Var. Agr, v. 2, n. 1, p. 2700-271, 1988.

QUADRO, M. F. L., L. H. R. MACHADO, S. CALBETE, N. N. M. BATISTA, G. SAMPAIO. Climatologia de Precipitação e Temperatura. Climanálise Especial - Edição Comemorativa de 10 anos. MCT/INPE/CPTEC, 1996.

ROUSE, J.W.; HAAS, R.W.; SCHELL, J.A.; DEERING, D.W.; HARLAN, J.C. Monitoring the Vernal Advancement and Retrogradation (Greenwave Effect) of Natural Vegetation. NASA/GSFCT Type III Final Report, Greenbelt, MD, 1974

SANTOS, F.B. Estimativa do Balanço de Energia Utilizando Imagens do Sensor TM/LANDSAT-5 no Baixo São Francisco. Dissertação de Mestrado em Meteorologia, Instituto de Ciências Atmosféricas/Universidade Federal de Alagoas, Maceió, 2012.

SANTOS, C.V.; CARVALHO, H.F.; SILVA, M.J.; DE MOURA, M.S.B.; GALVÍNCIO, J.D. et al. Uso de Sensoriamento Remoto na análise da temperatura da superfície em áreas de floresta tropical sazonalmente seca. Revista Brasileira de Geografia Física, v. 13, n. 3, p. 941-953, 2020.

SILVA, J.W.F.; SANTOS, R.L. Estimativa da temperatura da superfície do solo de uma região semi-árida a partir do IRMSS (banda 4) do CBERS-2. In: Anais do 13 Simpósio Brasileiro de Sensoriamento Remoto, Florianópolis: INPE, p. 1159-1166, 2007. 
SIMÕES, M.; FERRAZ, R.P.D.; ALVES, A.O. Integridade ecossistêmica a partir de dados de sensoriamento remoto e redes bayesianas. Revista Brasileira de Cartografia, v. 69, n. 3, p. 541-559, 2017.

SULLA-MENASHE, D.; FRIEDL, M.A.; KRANKINA, O.N.; BACCINI, A.; WOODCOCK, C.E.; SIBLEY, A.; SUN, G.; KHARUK, V.; ELSAKOV, V. et al. Hierarchical mapping of Northern Eurasian land cover using MODIS data. Remote Sensing of Environment, v. 115. n. 2, p. 392-403, 2011.

SULLA-MENASHE, D.; GRAY, J.M.; ABERCROMBIE, S.P.; FRIEDL, M.A. Hierarchical mapping of annual global land cover 2001 to present: The MODIS Collection 6 Land Cover product. Remote Sensing of Environment, v. 222, p. 183-1941, 2019.
VASCONCELOS, C.H.; NOVO, E.M.L.D.M.; DONALISIO, M.R. Uso do sensoriamento remoto para estudar a influência de alterações ambientais na distribuição da malária na Amazônia brasileira. Cadernos de Saúde Pública, v. 22, n. 1, p. 517-526, 2006.

WARREN, M.S.; PERES, L.; RODRIGUES, L.N.; CAMPANA, N.A. Procedimento para alteração da emissividade do produto de temperatura do MODIS-MOD11. Revista Brasileira de Cartografia, v. 63, n. 4, p. 465-474, 2012.

License information: This is an open-access article distributed under the terms of the Creative Commons Attribution License (type CC-BY), which permits unrestricted use, distribution and reproduction in any medium, provided the original article is properly cited. 